\title{
EL LUGAR DE LA CIENCIA EN LA CIVILIZACION MODERNA
}

\section{Thorstein Veblen}

Suele afirmarse que la moderna cristiandad es superior a todos los demás sistemas de vida civilizada. Otras edades y otras regiones culturales son consideradas, en cambio, inferiores, o bien más arcaicas o menos maduras. La cuestión es que la cultura moderna es superior en conjunto, es decir, no es que sea la mejor o la más elevada en todos sus aspectos y en cada una de sus facetas. No tiene, en efecto, una superioridad completa, sino una superioridad dentro de una serie estrictamente limitada de actividades intelectuales, mientras que, fuera de dicha serie, otras muchas civilizaciones superan a la de los modernos pueblos occidentales. No obstante, la peculiar excelencia de la cultura moderna es de tal naturaleza que le proporciona una decisiva ventaja práctica sobre todos los demás esquemas culturales que han existido antes o que han entrado en competencia con ella. Ha demostrado ser capaz de sobrevivir en su lucha por la existencia frente a aquellas otras civilizaciones que difieren de ella en sus rasgos distintivos.

La civilización moderna es particularmente realista. Contiene numerosos elementos que no responden a este carácter, mas estos otros elementos no son, en modo alguno, exclusivos de ella. Los modernos pueblos civilizados son capaces, en grado peculiar, de sostener una concepción impersonal y desapasionada de los hechos materiales a los que ha de enfrentarse la humanidad. Ello constituye precisamente la cumbre del desarrollo cultural. Comparado con este rasgo, el resto de cuanto comprende el esquema cultural es adven- 
ticio, o, todo lo más, es un subproducto de esta concienzuda comprensión de los hechos. Esta cualidad puede ser una cuestión de hábito o de dotes raciales, o bien un resultado de ambas cosas; pero, cualquiera que sea la explicación de su predominio, la consecuencia inmediata es la misma para el desarrollo de la civilización. Una civilización dominada por esta concepción realista debe prevalecer sobre cualquier esquema cultural que carezca de este elemento. Este rasgo de la civilización occidental llega a un punto decisivo en la ciencia moderna, y halla su más alta expresión material en la tecnología de la industria mecánica. En estas cosas la cultura moderna es creativa y autosuficiente; y, una vez sentado esto, el resto de lo que puede parecer característico de la civilización occidental se deduce fácilmente. La estructura cultural se apiña en torno a este cuerpo de conocimiento realista como su núcleo sustancial. Todo cuanto no esté en consonancia con estas opacas creaciones de la ciencia supone un intrusismo en el esquema moderno, que se inspira o se apoya en el pasado bárbaro.

Otros tiempos y otras gentes sobresalieron en otras cosas y son conocidos por otras virtudes. En el arte creativo, así como en el sentido crítico, el vacilante talento de la cristiandad puede, todo lo más, seguir el ejemplo de los antiguos griegos y de los japoneses. En habilidad manual, los artesanos del Oriente Medio, al igual que los del Extremo Oriente, se encuentran en un nivel seguramente superior al de las más altas realizaciones europeas, viejas o nuevas. En mitología, folclore y simbolismo oculto, muchos de los bárbaros más inferiores han alcanzado cosas más allá de cuanto los sacerdotes y poetas de nuestros días saben cómo plantearse. En el terreno de la metafísica y de la versatilidad dialéctica, muchos orientales, así como los escolásticos del Medioevo, sobrepasan fácilmente las más altas cimas del Pensamiento nuevo y de la Crítica superior. En el sentido de la perspicacia de las verdades religiosas, al igual que en la fe generosa en observancias devotas, los pueblos de la India o del Tíbet, o incluso los cristianos medievales, son avanzados maestros en comparación incluso con lo más selecto de la fe de los tiempos modernos. En sagacidad política, así como en lealtad bruta, irracional, más de uno de los antiguos pueblos dan pruebas de una capacidad a la que no puede aspirar ninguna nación moderna civilizada. En cuestión de belicosidad, los pueblos del Islam, los indios sioux y los «bárbaros del mar del Norte» han situado el listón por encima de todo lo alcanzado por los más enérgicos jefes militares civilizados.

Para los modernos hombres civilizados, especialmente en sus intervalos de sensata reflexión, todas estas cosas que distinguen a las civilizaciones bárbaras se les antojan de un valor dudoso, y exigen que se les demuestren las causas por las que no deberían ser despreciadas. No ocurre así con el conocimiento de los hechos. La creación de Estados y dinastías, la fundación de familias, la ambición de feudos, la propagación de credos y la creación de sectas, la acumulación de bienes, el consumo de cosas superfluas, todo ello se consideró en su tiempo justificado por sí mismo como fin, pero a los ojos de los moder- 
nos hombres civilizados, todas estas cosas resultan fútiles comparándolas con los logros de la ciencia. Van menguando en la estima de los hombres con el paso del tiempo, en tanto que los logros de la ciencia resultan cada vez mayores. En nuestros días existe la arraigada convicción de que «el incremento y la difusión del conocimiento entre los hombres» es un derecho y un bien irrevocable. Vista desde esta perspectiva, libre de las triviales perplejidades de la vida cotidiana, esta proposición no es puesta en duda en el horizonte de la cultura occidental, y ningún otro ideal cultural ocupa un lugar indiscutible similar en las convicciones de la humanidad civilizada.

En cualquier cuestión importante acerca de la cual haya que pronunciarse de una vez por todas, se acaba por apelar, de común acuerdo, al científico. La solución ofrecida en nombre de la ciencia es decisiva, siempre que no sea desechada por una investigación científica aún más minuciosa. Este estado de cosas puede no ser del todo afortunado, pero el hecho es así. Existen otros motivos de finalidad más antiguos que, probablemente, pueden ser mejores, más nobles, más enriquecedores, más profundos, más bellos. Se concibe que pueda ser preferible, en materia de ideales culturales, dejar la última palabra al abogado, al duelista, al sacerdote, al moralista o al colegio de heráldica. Antaño, la gente se contentaba con dejar sus asuntos más importantes a la decisión de cualquiera de estos tribunales, y, fuerza es reconocerlo, con muy felices resultados en aquellos aspectos que, a la sazón, gozaban del más alto predicamento. No obstante, cualquiera que haya podido ser el sentido común demostrado por las anteriores generaciones a este respecto, el sentido común moderno sostiene que la respuesta del científico es la única auténtica y definitiva. Como último recurso, el sentido común ilustrado se aferra a la verdad opaca, y rehúsa ir más allá de la evidencia proporcionada por los hechos tangibles.

Quasi lignum vitae in paradiso Dei, et quasi lucerna fulgoris in domo Domini, tal es el lugar de la ciencia en la civilización moderna. Esta fe actual en el conocimiento realista puede o no estar bien fundada. Ocurre que los hombres le conceden tan alto lugar tal vez por idolatría, o quizá en detrimento de los mejores y más íntimos intereses de la raza humana. Hay motivos para abrigar algo más que una vaga duda acerca de que este culto de la ciencia no sea del todo un desarrollo saludable, que la búsqueda implacable de este tipo de conocimiento realista no contribuya al malestar y al deterioro de la raza, en conjunto, tanto a causa de sus inmediatos efectos en la vida espiritual de la humanidad como de las consecuencias materiales que se derivan de un gran avance en el campo del conocimiento.

Sea como fuere, no se trata aquí de ahondar en este asunto. La cuestión que ahora nos ocupa es la siguiente: ¿cómo ha surgido este culto de la ciencia? ¿Cuáles son sus antecedentes culturales? ¿Hasta qué punto está en consonancia con la naturaleza humana hereditaria? ¿Qué tipo de influencia tiene en las convicciones de los hombres civilizados?

$\mathrm{Al}$ ocuparse de los problemas pedagógicos y de la teoría de la educación, la 
psicología actual coincide casi unánimemente en decir que todo conocimiento es de carácter «pragmático»; que el conocimiento es una acción rudimentaria, rudimentariamente encaminada a un fin; que todo conocimiento es «funcional»; que tiene una naturaleza utilitaria. Esto, naturalmente, es sólo un corolario del principal postulado de los psicólogos actuales, cuyo lema es que la Idea es esencialmente activa. No es necesario enfrentarse a esta escuela «pragmática» de psicólogos. Es posible que su aforismo no encierre toda la verdad, pero al menos se acerca más al corazón del problema epistemológico que cualquier otra formulación anterior. Puede decirse que es así porque, por una parte, su argumento responde a las exigencias de la ciencia moderna. Se trata de un concepto del que puede hacerse uso efectivo en el terreno de la ciencia realista; está elaborado en unos términos que son, en última instancia, de carácter impersonal, por no decir tropismático; tal y como lo exige la ciencia, con su insistencia en la causa y el efecto opacos. En tanto que el conocimiento está construido en términos teleológicos, en términos de interés y atención personales, esta aptitud teleológica es en sí misma reducible a un producto de la selección natural no teleológica. La inclinación teleológica de la inteligencia es un rasgo hereditario impuesto a la raza por la acción selectiva de fuerzas que no persiguen por sí mismas un fin. Los fundamentos de la inteligencia pragmática no son pragmáticos, ni tampoco personales o apreciables.

Este carácter impersonal de la inteligencia es, desde luego, más evidente en los niveles inferiores de vida. Si seguimos a Loeb, por ejemplo, en sus investigaciones sobre la psicología de esa vida que subyace en el umbral de la inteligencia, nos encontramos con que se trata de una respuesta motora, sin propósito fijo, aunque constante, al estímulo ${ }^{1}$. La respuesta es de la naturaleza de un impulso motor y, en este sentido, es «pragmática», si es que puede ser calificada de este modo una fase tan rudimentaria de la sensibilidad. En consecuencia, el organismo que responde debe de ser llamado «agente». Sólo por expresarse de alguna forma se han creado estos términos para aplicarlos a las reacciones tropismáticas. En un lugar más elevado dentro de la escala de la sensibilidad y de la complicación nerviosa, los instintos actúan con un resultado similar. En el plano humano, la inteligencia (el efecto selectivo de la complicación inhibidora) puede proporcionar la respuesta en la forma de una línea razonada de conducta tendente a un resultado que será conveniente para el agente. Se trata de un pragmatismo ingenuo de la especie desarrollada. Ya no existe una pregunta, sino que el organismo que responde es un «agente», y su respuesta inteligente al estímulo es de carácter teleológico. Mas esto no es todo. La complicación nerviosa inhibidora puede también provocar otra cadena de respuestas al estímulo dado, que no se autodesgasta en una línea de conducta motora, y que no cae en un sistema de utilizaciones. Pragmáticamente hablando, esta remota cadena de respuestas es inesperada e irrelevante. Excepto en casos apremiantes, semejante respuesta ociosa suele estar presente como un fenómeno secundario. Si hemos de abundar en la creencia de que la

1 Jacques LoєB, Heliotropismus der Thiere y Comparative Psychology and Pbysiology of the Brain. 
inteligencia es, en sus elementos, de la naturaleza de una selección inhibidora, parece necesario presuponer que algunas de estas cadenas de respuestas, ociosas e irrelevantes, son responsables del curso ulterior de los elementos eliminados, al dar a la respuesta motora el carácter de una línea razonada de conducta. De forma que, asociada con la atención pragmática, se encuentra una atención más o menos irrelevante, o una curiosidad ociosa. Más particularmente, éste es el caso cuando nos hallamos ante un nivel de inteligencia mayor. Tal vez esta curiosidad ociosa esté estrechamente relacionada con la aptitud para jugar, observada tanto en los hombres como en los animales inferiores ${ }^{2}$. Esta aptitud para el juego, así como el funcionamiento de la curiosidad ociosa, parece estar particularmente viva en los jóvenes, cuya aptitud para un pragmatismo continuado es; al mismo tiempo, relativamente vaga y desconfiable.

Esta curiosidad ociosa no formula su respuesta al estímulo en términos de una línea conveniente de conducta, ni incluso necesariamente en una cadena de actividad motora, sino en términos de la secuencia de actividades que se están desarrollando de manera continua en los fenómenos observados. La «interpretación» de los hechos bajo la guía de esta curiosidad ociosa puede adquirir la forma de explicaciones antropomórficas o animistas de la «conducta» de los objetos observados. La interpretación de los hechos adquiere una forma dramática. Los hechos se conciben de un modo animista, y se les atribuye una intención pragmática. Se construye su comportamiento como un proceso razonado por ellos mismos, tendente bien a beneficiar a estos objetos concebidos de forma animista, bien al logro de algún fin para el que estos objetos han sido concebidos.

Entre los pueblos salvajes y bárbaros inferiores existe, por regla general, un amplio caudal de conocimientos organizados de este modo en mitos y leyendas, que no necesitan tener un valor pragmático para quienes los aprenden, y que no pretenden influir en su conducta con respecto a los asuntos prácticos. Pueden llegar a tener un valor práctico para ellos como terreno de observancias supersticiosas, pero pueden también no tenerlo ${ }^{3}$. Todos los estudiosos de las culturas inferiores son conscientes del carácter dramático de los mitos vigentes en estos pueblos, y saben también que, sobre todo en las comunidades pacíficas, el gran acervo de la tradición mítica es de tipo ocioso, ya que tiene escasa influencia en la conducta práctica de quienes creen en estos mitos-dramas. De una parte, los mitos y, de otra, el conocimiento cotidiano de costumbres, materiales, herramientas y conveniencias, pueden ser casi independientes entre sí. Especialmente, tal es el caso entre aquellos pueblos en los que prevalece una forma pacífica de vida, entre quienes los mitos no han sido, en gran medida, canonizados como precedentes de la malevolencia divina.

Cfr. Gross, Spiele der Thiere, cap. 2 (esp. pp. 65-76) y cap. 5; The Play of Man, Parte III, sec. 3; Spencer, Principles of Psychology, secs. 533-535.

${ }^{3}$ Los mitos y la tradición legendaria de los esquimales, los indios Pueblo y algunas tribus de la costa noroeste ofrecen buenos ejemplos de tales creaciones ociosas. Ver varios Reports del Bureau of American Etbnology; también, p. ej., TyLor, Primitive Culture, esp. los capítulos sobre «mitología» y «animismo». 
El conocimiento del bárbaro inferior de los fenómenos de la naturaleza, en cuanto son objeto de una especulación deliberada y están organizados en un corpus consistente, es de la naturaleza de ciclos biológicos. En su mayor parte, este corpus de conocimiento se organiza según una curiosidad ociosa. En la medida en que está sistematizado de acuerdo con los cánones de la curiosidad, más que por la conveniencia, la prueba de verdad aplicada a todo este corpus de conocimientos bárbaros es la prueba de la consistencia dramática. Además de su cosmología dramática y de las leyendas populares, es ocioso decir que estos pueblos poseen también, de una manera más o menos sistemática, un considerable caudal de sabiduría mundana, cuya prueba de validez es la utilidadt.

El conocimiento pragmático de los primeros días apenas si difiere en su carácter del de las fases más maduras de la cultura. Sus mayores logros en materia de formulación sistemática consisten en exhortaciones didácticas al ahorro, la prudencia, la ecuanimidad y hábil administración, es decir, un conjunto de máximas de conducta conveniente. En este campo apenas existe adelanto desde Confucio a Samuel Smiles. Por otra parte, bajo la guía de la curiosidad ociosa, se ha producido un constante avance hacia un sistema cada vez más global de conocimiento. Con el avance de la inteligencia y de la experiencia, se alcanza una observación más minuciosa y un análisis más detallado de los hechos 5 . La dramatización de la secuencia de los fenómenos puede adoptar entonces formulaciones algo menos personales, menos antropomórficas, de los procesos observados; pero en ninguna fase de su desarrollo - al menos en ninguna fase alcanzada hasta ahora- pierde su carácter dramático el resultado de este proceso de la curiosidad ociosa. Se hacen generalizaciones globales y se construyen cosmologías, pero siempre de forma dramática. Se establecen principios generales de explicación, que en los primeros días de especulación teórica parecen volver invariablemente al amplio principio vital de la generación. La procreación, el nacimiento, el desarrollo y la decadencia constituyen el ciclo de postulados en cuyo ámbito discurren los procesos de los fenómenos naturales. La creación es procreación en estos arcaicos sistemas teóricos, y la causalidad es gestación y nacimiento. Los arcaicos esquemas cosmológicos de Grecia, India, Japón, China, Polinesia y América, responden todos ellos al mismo efecto general ${ }^{6}$.

4 «Pragmático» se utiliza aquí en un sentido más restringido del que la escuela pragmática característica de los psicólogos modernos suele dar al término. «Pragmático», «teológico» y términos similares se han utilizado para aludir a la imputación de propósito, así como a la capacidad de uso. Con esto no se pretende criticar esta utilización ambigua de términos, ni tampoco corregirla; pero, aquí, los términos se emplean sólo en el último sentido, que les pertenece exclusivamente en razón de la etimología y del uso que desde siempre se hizo de ellos. Por tanto, el conocimiento «pragmático» es aquel concebido para servir a un fin conveniente para el conocedor, y se contrasta aquí con la imputación de conducta conveniente a los hechos observados. La razón para preservar esta distinción es simplemente la actual necesidad de un término sencillo mediante el cual señalar la distinción entre el saber mundano y el saber ocioso.

5 Cfr. Ward, Pure Sociology, esp. pp. 437-448.

"Cfr, por ejemplo, Tylor, Primitive Culture, cap. 8. 
A través de esta especulación biológica está presente, de modo recóndito y en un segundo plano, el reconocimiento tácito de una causalidad material, como, por ejemplo, las condiciones de las operaciones comunes propias de la dinámica de la vida laboral cotidiana. Pero esta relación causal entre el trabajo común y su producto se acepta sin más, no se hace de ella un principio para la generalización global. Se pasa por alto como un hecho trivial. Las generalizaciones superiores se inspiran en las características más amplias del actual esquema de vida. Los hábitos de pensamiento imperantes en la elaboración de un sistema de conocimiento son aquellos que fomentan los acontecimientos más impresionantes de la vida, la estructura institucional en la cual vive la comunidad. Y mientras que las instituciones dominantes sean las de consanguinidad, descendencia y discriminación de clan, los cánones del conocimiento serán los de la misma clase.

Cuando se produce una transformación en un esquema de cultura que pasa de una vida apacible con esporádica depredación a un esquema establecido de vida rapaz, ocasionando dominio y servidumbre, gradaciones de privilegio y de honor, coacción y dependencia personal, entonces el esquema del conocimiento experimenta un cambio análogo. La cultura depredadora, o bárbara superior, es peculiar, para nuestro propósito, en cuanto está regida por un acentuado pragmatismo. Las instituciones de esta fase cultural son relaciones convencionales de fuerza y de fraude. Los problemas de la vida son problemas de conducta conveniente, puesto que discurren según las vigentes relaciones de dominio y de sumisión. Las distinciones habituales son distinciones de fuerza personal, ventaja, prioridad y autoridad. Una atinada adaptación a este sistema de dignidad y servidumbre jerarquizadas se convierte en asunto de vida o muerte, y los hombres aprenden a pensar en estos términos de forma definitiva. El sistema de conocimiento, aunque sus motivos sean hasta ahora de índole imparcial u ociosa, incurre en términos similares, porque tales son los hábitos de pensamiento y los criterios de discriminación impuestos por la vida cotidiana?.

El trabajo teórico de una era cultural de estas características, como por ejemplo la Edad Media, reviste también la misma forma general de representación, pero los postulados de las teorías dramáticas y las pruebas de validez teórica ya no son los mismos que regían antes de que el esquema de servidumbre jerarquizada llegase a ocupar este lugar. Los cánones que rigen el proceso de la curiosidad ociosa ya no son los de generación, consanguinidad y vida familiar, sino, antes bien, los de dignidad jerarquizada, autenticidad y dependencia. Las generalizaciones superiores adquieren un nuevo aspecto, lo cual puede suceder sin desprenderse formalmente de las antiguas creencias. Las cosmologías de estos bárbaros superiores se forjan en términos de una jerarquía feudal de agentes y elementos, y el nexo causal entre los fenómenos se concibe de forma animista, a la manera de una magia favorable. Las leyes que se espera descubrir en el universo natural se buscan como si fueran decretos

Cfr. James, Psychology, cap. 9, esp. sec. 5. 
impuestos por las autoridades. La relación en la cual se concibe que la divinidad, o divinidades, afrontan los hechos ya no es la relación de un progenitor, sino una relación de soberanía. Las leyes naturales se entienden como una consecuencia de las normas arbitrarias de la situación impuesta al universo natural por una Providencia todopoderosa con vistas al mantenimiento de su propio prestigio. La ciencia que se desarrolla en este ambiente espiritual es del tipo de la que representan la alquimia y la astrología, en las que el grado de nobleza y prepotencia atribuido a los objetos, y la fuerza simbólica de los nombres de éstos, tienden a buscar una explicación de lo que está teniendo lugar.

El resultado teórico de los escolásticos tiene necesariamente un acusado carácter pragmático, ya que todo el esquema cultural según el cual vivieron y trabajaron tenía un poderoso carácter pragmático. Los conceptos vigentes de las cosas fueron, por tanto, elaborados en términos de conveniencia, fuerza personal, proeza, autoridad establecida, etc., y esta variedad de conceptos fue empleada por la fuerza de la costumbre en la correlación de hechos para propósitos de conocimiento, incluso cuando no se esperaba hacer un inmediato uso práctico del conocimiento adquirido de esta manera. Al mismo tiempo, una gran proporción de las investigaciones y especulaciones escolásticas tendían directamente a normas de conducta conveniente, aunque revistiesen la forma de una filosofía de la vida según leyes y costumbres temporales, o de un esquema de salvación bajo los dictados de una Providencia autocrática. Una comprensión ingenua de la máxima según la cual todo conocimiento es pragmático, hallaría una corroboración más satisfactoria en el resultado intelectual de la escolástica que en cualquier otro sistema de conocimiento anterior o posterior.

Con el advenimiento de la época moderna, se produce un cambio en la naturaleza de las investigaciones y de las formulaciones elaboradas bajo la dirección de la curiosidad ociosa, de la que, a partir de esta época, se habla con frecuencia designándola como espíritu científico. El cambio en cuestión guarda estrecha relación con un cambio análogo en las instituciones y en las costumbres cotidianas, sobre todo con los cambios que la era moderna introduce en la industria y en la organización económica de la sociedad. Es dudoso que se pueda hablar de los intereses intelectuales y de las enseñanzas característicos de la nueva era diciendo que son menos «pragmáticos», en la acepción que algunas veces se da al término, que los de los tiempos de la escolástica; sucede que son de otra clase, ya que están condicionados por una diferente situación cultural e industrial ${ }^{8}$. En la vida de la nueva era, las concepciones de rango auténtico y de dignidad diferencial se han debilitado en los asuntos

8 Tal como se emplea comúnmente, el término «pragmático» abarca tanto la conducta tendente a la ventaja preferencial del agente, conducta conveniente, como la habilidad encaminada a la producción de cosas que pueden redundar o no en beneficio del agente. Si el término es entendido según este último significado, la cultura de los tiempos modernos no es menos «pragmática» que la de la Edad Media. Aquí se utiliza en su primera acepción. 
prácticos, y las nociones de realidad preferencial y de tradición auténtica, de modo similar, cuentan menos también en la nueva ciencia. Las fuerzas que trabajan en el mundo exterior se conciben de una forma menos animista, aunque todavía prevalezca el antropomorfismo, por lo menos en el grado necesario para dar una interpretación dramática de la secuencia de los fenómenos.

Los cambios en la situación cultural que parecen haber tenido consecuencias más serias para los métodos y la intención de la investigación científica son aquellos que se produjeron en el campo de la industria. En los primeros tiempos de la época moderna la industria es un hecho de preponderancia relativamente superior a la que tenía durante el régimen feudal. Este es un rasgo característico de la cultura moderna, lo mismo que el heroísmo y la lealtad fueron rasgos culturales característicos de los tiempos anteriores. Esta industria moderna pionera es, en un grado lógico y convincente, una cuestión de trabajo bien hecho. No sucedió antes así, ni tampoco a partir de entonces. El artesano, más o menos hábil, y con una capacidad más o menos especializada, era la figura central de la situación cultural de la época, y por tanto los conceptos de los científicos fueron elaborados a imagen y semejanza del artesano. Las dramatizaciones de la secuencia de los fenómenos externos desarrolladas bajo el impulso de la curiosidad ociosa fueron, a la sazón, concebidas en términos de trabajo bien hecho. El trabajo bien hecho suplantó gradualmente a la dignidad diferencial como el canon autorizado de verdad científica, incluso en los niveles superiores de especulación e investigación. Esto, naturalmente, equivale a decir, en otras palabras, que se le dio prioridad a la ley de causa y efecto, en contraste con la consistencia dialéctica y la tradición auténtica. Mas esta primitiva-moderna ley de causa y efecto - la ley de las causas eficientes- es de tipo antropomórfico. «Causas similares producen efectos similares», o sea, la producción del hombre hábil, del artesano, es como el artesano; «nada se encuentra en el efecto que no estuviese contenido en la causa».

Estas afirmaciones son, desde luego, más antiguas que la ciencia moderna, pero es sólo en los primeros días de ésta cuando empiezan a imperar con una influencia indiscutible, dejando de lado los fundamentos superiores de validez dialéctica. Invaden incluso los más altos y recónditos terrenos de especulación, de forma que, al aproximarse la transición de los primeros tiempos de la edad moderna al último período, en el siglo xviII, llegan hasta determinar los consejos de los teólogos. La divinidad, tras haber adoptado en el Medioevo esencialmente la forma de un señor feudal preocupado por el mantenimiento de su propio prestigio, se convierte en un creador ocupado en hacer cosas útiles para los hombres. Su relación con respecto al hombre y al universo natural ya no es, principalmente, la de un progenitor, como lo era en la cultura bárbara inferior, sino la de un mecánico con talento. Las «leyes naturales», que en tanta consideración tenían los científicos de aquella era, ya no son decretos emitidos por una autoridad legislativa preternatural, sino, más bien, detalles de las especificaciones elaboradas por el maestro para guía de los 
artesanos que llevan a cabo sus designios. En la ciencia del siglo XVIII, estas leyes naturales son leyes que especifican la secuencia de causa y efecto, y soportan esta caracterización como una interpretación dramática de la actividad de las causas actuantes, causas éstas que se conciben de una manera cuasipersonal. En tiempos modernos posteriores, las formulaciones de secuencia causal se desarrollan de forma más impersonal y objetiva, más realista, pero la imputación de actividad a los objetos observados nunca cesa, y, hasta en las últimas y más maduras formulaciones de la investigación científica, no se pierde del todo el tono dramático. Las causas en juego se conciben de una manera en extremo impersonal, pero hasta ahora ninguna ciencia (excepto, ostensiblemente, las matemáticas) se ha contentado con realizar su trabajo teórico tan sólo en términos de magnitud inerte. Continúa atribuyéndose actividad a los fenómenos con los que la ciencia tiene que habérselas; y la actividad no es, naturalmente, un hecho de observación, sino que es el observador quien se la imputa a los fenómenos ${ }^{\vartheta}$. Por supuesto, quienes insisten en una formulación puramente matemática de las teorías cientificas, lo niegan pero el mantenimiento de tal negativa pone en tela de juicio su coherencia. Aquellas eminentes autoridades que preconizan una formulación matemática incolora, tan pronto como se dedican al trabajo real de investigación científi$\mathrm{ca}^{10}$, recurren, invariable y necesariamente, a la preconcepción (esencialmente metafísica) de causalidad.

Como la tecnología mecánica ha realizado grandes avances durante el siglo XIX, convirtiéndose en una fuerza natural de vastas consecuencias, las formulaciones de la ciencia se han orientado en la dirección de un realismo impersonal. El proceso mecánico ha desplazado al obrero como el arquetipo a cuya imagen se concibe la causalidad por los investigadores científicos. En consecuencia, la interpretación dramática de los fenómenos naturales se ha vuelto menos antropomórfica; ya no construye el ciclo biológico de una causa en acción para producir un efecto dado - a la manera en que un obrero hábil produce un artículo bien elaborado-, sino que construye el ciclo biológico de un proceso en el que la distinción entre causa y efecto apenas si necesita ser observada de forma detallada y específica, en el que el curso de la causalidad se despliega por sí mismo en una secuencia ininterrumpida de cambio acumulativo. En contraste con las formulaciones pragmáticas del saber mundano, estas recientes teorías de los científicos parecen muy opacas, impersonales y realistas; pero, consideradas por sí mismas, hay que admitir, no obstante, que demuestran las limitaciones de los ensueños dramáticos por los que antaño se guiaban los creadores de mitos salvajes.

'Epistemológicamente hablando, se atribuye actividad a los fenómenos con el propósito de organizarlos en un sistema dramáticamente consistente.

11) Cfr., por ejemplo, Karl Pearson, Grammar of Science, y compárese su ideal de magnitudes inertes, tal como se establece en su exposición, con su actual trabajo tal como aparece en los caps. 9, 10 y 12, y más especialmente en sus discusiones sobre «Mother Right» y temas relacionados en The Chances of Death. 
Por lo que respecta a las miras y a la intención de la investigación científica, consideradas desde el punto de vista del científico, se da la coincidencia, fortuita e intrascendente, de que gran parte del conocimiento obtenido según los cánones mecánicos de investigación pueden servir a los intereses prácticos. Gran parte de este conocimiento es útil, o puede hacerse que lo sea, mediante su aplicación al control de los procesos en los que intervienen las fuerzas naturales. Esta utilización del conocimiento científico para fines útiles en tecnología, incluye, en el más amplio sentido de la palabra, además de la industria mecánica propiamente dicha, ramas prácticas tales como la ingeniería, la agricultura, la medicina, la higiene y las reformas económicas. La razón por la cual las teorías científicas pueden ser aplicadas a estos fines prácticos no es que estos fines estén incluidos en el objetivo de la investigación científica. Estos propósitos útiles están al margen del interés del científico. No es que él persiga, o pueda perseguir, las mejoras tecnológicas. Su investigación es tan «ociosa» como la del creador de mitos de los indios Pueblo. Pero las normas de validez conforme a las cuales desarrolla su trabajo son aquellas impuestas por la moderna tecnología, a través de la habituación a sus exigencias, y, por tanto, los resultados que obtiene son utilizables para los propósitos tecnológicos. La situación cultural es la que configura los cánones de validez del científico; se trata de hábitos de pensamiento que le son impuestos por el esquema de vida imperante en la comunidad en la que vive; $y$, en condiciones modernas, este esquema de vida está, en gran parte, dominado por las máquinas. En la cultura moderna, la industria, los procesos y los productos industriales han ido imponiéndose progresivamente a la humanidad, hasta el punto de que estas creaciones del ingenio del hombre han llegado a ocupar el lugar predominante en el esquema cultural; y no es exagerado decir que se han convertido en la fuerza principal moldeadora de la vida cotidiana de los hombres, $y$, por consiguiente, en el factor primordial en la configuración de sus hábitos de pensamiento. De aquí que el hombre haya aprendido a pensar en los términos en los que actúan los procesos tecnológicos. Esto es particularmente cierto por lo que respecta a aquellos hombres que, en virtud de una sensibilidad especialmente fuerte en este sentido, se convirtieron en adictos a ese hábito de indagación realista que constituye la investigación científica.

La tecnología moderna utiliza la misma gama de conceptos, piensa en los mismos términos, y aplica las mismas pruebas de validez que la ciencia moderna. En ambas, los términos de estandarización, validez y finalidad son siempre términos de secuencia impersonal, en vez de términos de naturaleza humana o de agentes preternaturales. De ahí la estrecha asociación entre las dos. La ciencia y la tecnología van de la mano. El proceso de la naturaleza, de que trata la ciencia y del que saca provecho la tecnología; la secuencia de los cambios en el mundo exterior, animado e inanimado, discurren en términos de causalidad bruta, al igual que las teorias de la ciencia. Estos procesos no tienen en cuenta, en absoluto, la conveniencia o la inconveniencia humanas. Para hacer uso de ellos han de ser tomados tal como son, opacos e insensibles. En consecuencia, 
la tecnología procede en la actualidad de acuerdo con una interpretación de estos fenómenos en términos mecánicos, no en términos de personalidad imputable, ni tampoco de habilidad. La ciencia moderna, cuyos conceptos derivan de la misma fuente, lleva a cabo sus investigaciones y expone sus conclusiones con el mismo carácter objetivo con que lo hace el ingeniero mecánico.

De esta forma ha llegado a suceder, a través del cambio progresivo de los hábitos que rigen el pensamiento de la comunidad, que, desde el advenimiento de la era moderna, las teorías científicas hayan divergido progresivamente de las formulaciones del pragmatismo. Partiendo de un conocimiento organizado sobre la base de una imputable propensión personal o animista, la teoría ha pasado a basarse solamente en una imputación de actividad bruta, y esta última se concibe de una forma cada vez más realista; hasta que, últimamente, la esfera pragmática de conocimiento y la esfera científica han llegado a estar cada vez más distanciadas, y difieren no sólo en sus metas, sino también en su intención. En ambos dominios el conocimiento discurre en términos de actividad, pero, por un lado, se trata del conocimiento de aquello que se ha hecho mejor y, por otro, conocimiento de lo que sucede; de una parte, el conocimiento de formas y de medios y, de otra, el conocimiento sin ningún otro propósito ulterior. Esta última esfera del conocimiento puede servir a los fines de la primera, pero lo contrario no es cierto.

Estas dos esferas divergentes de investigación se encuentran en todas las fases de la cultura humana. Lo que distingue a la fase presente es que la discrepancia entre ambas es ahora mayor que antes. La presente era cultural no se distingue en modo alguno de las demás por una excepcional urgencia o perspicacia en la búsqueda de conveniencias pragmáticas. Tampoco es prudente afirmar que la presente civilización supera a todas las demás en el volumen o en la ejecución de ese caudal de conocimientos que se le deben reconocer a la curiosidad ociosa. Lo que distingue a la presente civilización en lo que respecta a estas premisas es: 1) que la primacía en el esquema cultural ha pasado del pragmatismo a la investigación desinteresada cuya motivación es la curiosidad ociosa, y 2) que, en el campo de esta última, la creación de mitos y leyendas en términos de personalidad imputada, así como la construcción de sistemas dialécticos en términos de realidad diferencial, ha cedido el primer puesto a la elaboración de teorías en términos de secuencia realista ${ }^{11}$.

El pragmatismo no crea sino máximas de conducta conveniente. La ciencia no crea sino teorías ${ }^{12}$. No sabe nada de política o de utilidad, de lo mejor o de lo peor. Nada de todo ello figura en lo que hoy día es el conocimiento científico relevante. La sabiduría y la competencia de tipo pragmático no contribuyen al progreso de un conocimiento de hecho. Tienen tan sólo una influencia incidental en la investigación científica, y esta influencia es, ante

11 Cfr. James, Psychology, vol. II, cap. 28, pp. 633-671, especialmente la nota de la p. 640 .

12 Cfr. Ward, Principles of Psychology, pp. 439-443. 
todo, de inhibición y de dirección errónea. Dondequiera que se pretenda introducir por la fuerza normas de conveniencia en la investigación, la consecuencia será desdichada para la ciencia, por afortunada que pueda resultar para otros propósitos ajenos a la misma. La actitud mental del saber mundano persigue objetivos opuestos al espíritu científico desinteresado, y su búsqueda induce un sesgo intelectual que es incompatible con la concepción científica. Su producto intelectual es un caudal de juiciosas normas de conducta, en gran parte tendentes a sacar provecho de la debilidad humana. Sus términos habituales de estandarización y validez son términos de naturaleza, preferencia, prejuicio, aspiración, esfuerzo e incapacidad humanos, y la pauta de pensamiento que los acompaña está en consonancia con dichos términos. No cabe duda de que la intención pragmática, ampliamente difundida en las civilizaciones europeas y no europeas más antiguas, ha sido lo que más ha influido en el avance relativamente reducido y lento del conocimiento científico. En el esquema moderno del conocimiento es indudable que, de forma similar y con análogo efecto, la formación en teología, en derecho y en las ramas afines de la diplomacia, en las tácticas comerciales, o en los asuntos militares y en la teoría política, es ajena al espíritu científico escéptico, y subversiva con respecto a éste.

El moderno esquema de cultura comprende un amplio corpus de saber mundano, y también de ciencia. Este saber pragmático se mantiene vigilante contra la ciencia con una cierta reserva envidiosa. Los pragmatistas se valoran a sí mismos, en buena medida, por ser útiles y eficaces tanto en lo bueno como en lo malo. Se dan cuenta del antagonismo existente entre ellos y los científicos, y albergan ciertas dudas con respecto a éstos, es decir, piensan que no son sino unos simples personajes frívolos y decorativos, aunque algunas veces se arroguen el prestigio del hombre de ciencia, cosa que les viene muy bien, ya que la esencia de la sabiduría mundana consiste en apropiarse de algo de lo que se pueda sacar provecho. En estos campos, el razonamiento gira en torno a cuestiones de beneficio personal - de la clase que sea, y los méritos de las pretensiones examinadas en estas discusiones se deciden en términos de autenticidad-. Las pretensiones personales constituyen el objeto de la investigación, y estas pretensiones se construyen y se deciden en términos de precedente y elección, uso y costumbre, autoridad establecida, etc. Los principales logros de generalización en estas indagaciones pragmáticas son del tipo de las deducciones de tradición auténtica, y la formación en esta clase de razonamiento produce discriminación respecto de la autenticidad y la conveniencia. El hábito de pensamiento resultante es la inclinación a sustituir las explicaciones de facto por las distinciones dialécticas y las decisiones de jure. Las llamadas «ciencias» asociadas con estas disciplinas pragmáticas, tales como la jurisprudencia, las ciencias políticas, etc., constituyen taxonomías de creencias. De este carácter era la mayor parte de la «ciencia» cultivada por los escolásticos, y, naturalmente, todavía se encuentran numerosos vestigios de este tipo de convicciones auténticas entre los principios de los científicos, especialmente en las ciencias 
sociales, concediéndose aún no poca importancia al hecho de cultivarlas. Sustancialmente, la «ciencia» de la divinidad tiene, desde luego, el mismo valor que el que corresponde a las indagaciones pragmáticas temporales. En ella, las preguntas a las cuales se busca respuesta, así como los objetivos y el método de investigación, poseen el mismo carácter pragmático, aunque el razonamiento discurra en un plano más elevado de personalidad, y ambicione una solución en términos de una conveniencia más remota y más metafísica.

A la luz de cuanto se ha dicho más arriba, cabe repetir las siguientes preguntas: chasta qué punto la búsqueda científica del conocimiento realista está en consonancia con las aptitudes intelectuales heredadas y las inclinaciones del hombre común?, y ¿cuál es la posición que ocupa la ciencia en la cultura moderna? La primera es una cuestión relativa a la herencia temperamental de la humanidad civilizada, y, por tanto, es, en gran medida, una cuestión de las circunstancias que en el pasado forjaron selectivamente la naturaleza de ésta. Durante la cultura bárbara, así como en los niveles inferiores de la comúnmente llamada vida civilizada, la nota dominante ha sido la de la conveniencia competitiva, a mayor o a menor nivel, para el individuo o el grupo, en una lucha declarada por los medios de vida. Tal sigue siendo el ideal del político y del hombre de negocios, y también el de otras clases, cuyos hábitos de vida les llevan a aferrarse a las tradiciones bárbaras heredadas. La cultura del bárbaro superior y del civilizado inferior, como ya se ha indicado, es pragmática de una forma tan completa que casi rechaza completamente todo ideal de vida o de conocimiento no pragmáticos. Cuando esta tradición es poderosa, sólo existe una precaria oportunidad de realizar un esfuerzo coherente para formular el conocimiento en otros términos que no sean los establecidos por las relaciones imperantes de dominio y superioridad personales, y por los ideales de ganancia personal.

Durante la Edad de las tinieblas y en los primeros años del Medioevo, por ejemplo, es cierto que, en general, cualquier corriente de pensamiento no controlada por consideraciones de conveniencia y prejuicios de status sólo se encuentra en las profundas oscuridades de la vida común, entre los estratos menospreciados de la población que vivían fuera del alcance de la lucha de clases activa. Lo que pervive de esta producción intelectual común, no pragmática, reviste la forma de leyendas y cuentos costumbristas, a menudo embellecidos en los documentos auténticos de fe. Estos resultan menos ajenos a la cultura más reciente y más elevada de la Cristiandad de cuanto lo son las producciones dogmáticas, dialécticas y caballerescas que ocupaban la atención de las clases más altas en tiempos medievales. Puede parecer una curiosa paradoja que el florecimiento posterior y más perfecto de la civilización occidental esté más próximo a la vida espiritual de los siervos y de los villanos que a la de los grandes dominios o de las abadías. La vida cortesana y los usos caballerescos de pensamiento de aquella fase cultural del pasado apenas han dejado huella en el esquema cultural de los primeros tiempos modernos. Incluso los novelistas, que ostensiblemente se inspiran en el fenómeno de la 
caballería, hacen que, de modo inevitable, sus caballeros y sus damas se expresen según el lenguaje y los sentimientos de los barrios bajos de aquel entonces, suavizados por ciertas reflexiones y especulaciones modernas. Las proezas, las necedades de buen tono y las imbecilidades devotas de la alta sociedad medieval serían insufribles para la inteligencia moderna, incluso para la más mezquina y romántica. Por tanto, en una edad más avanzada, menos bárbara, se atesoran los precarios vestigios de la tradición popular que nos han llegado a través de tan común conducto — semisalvaje y semipagano, con esta última característica más acusada aun que la primera-, por encerrar las mayores conquistas espirituales que las edades bárbaras de Europa pueden ofrecer.

La influencia del pragmatismo bárbaro ha sido, en todo el mundo occidental, relativamente breve y leve; las únicas excepciones podrían hallarse en ciertos lugares del mar Mediterráneo. Pero dondequiera que la cultura bárbara ha sido lo suficientemente longeva y profunda como para ejercer un efecto selectivo sobre el material humano a ella sometido, cabe esperar que la intención pragmática se haya convertido en predominante y haya inhibido cualquier movimiento en la dirección de la indagación científica, eliminando toda aptitud efectiva para cualquier otra cosa que no sea el saber mundano. Lo que las consecuencias selectivas de tan prolongado régimen de pragmatismo suponen para el temple de la raza puede apreciarse en los vestigios humanos dejados por las grandes civilizaciones de la Antigüedad, tales como Egipto, la India y Persia. La ciencia no aparece entre estos vestigios del barbarismo. Durante su largo y arraigado dominio, la cultura bárbara ha creado selectivamente una tendencia temperamental y un esquema de vida del que está virtualmente excluido el conocimiento realista, en beneficio del pragmatismo secular y religioso. No obstante, para la inmensa mayoría de la raza, al menos para la mayor parte de la humanidad civilizada, el régimen de la cultura bárbara madura ha sido de duración relativamente corta, y, en consecuencia, ha tenido un efecto selectivo superficial y transitorio. No ha tenido fuerza ni tiempo para eliminar ciertos elementos de la naturaleza humana transmitidos por una anterior fase de vida, los cuales no están en total consonancia con la intención bárbara ni con las exigencias del esquema pragmático de pensamiento. Por tanto, el pensamiento pragmático bárbaro no es, propiamente dicho, un rasgo temperamental de los pueblos civilizados, excepto, tal vez, dentro de los límites de una cierta casta (como, por ejemplo, la nobleza alemana). Es, antes bien, una tradición, y no constituye una tendencia tan tenaz como para progresar contra la poderosa corriente materialista de las condiciones modernas y echar a un lado el creciente y urgente recurso a las concepciones realistas que contribuyen a la primacía de la ciencia. La humanidad civilizada sólo en escasa medida retrocede atávicamente a la forma de pensamiento de la alta época bárbara. El tiempo de los bárbaros ocupa un segmento demasiado pequeño del ciclo biológico de la raza como para haber dado un resultado temperamental duradero. La implacable disciplina bárbara en Europa afectó a una proporción relativamente pequeña de la población, y, 
en el transcurso del tiempo, este elemento elegido de la población se mezcló y fusionó con elementos inferiores, cuya vida continuaba discurriendo por los cauces del salvajismo, antes bien que por los de la fenecida cultura bárbara que había dado origen al esquema de vida caballeresco.

De las diversas fases de la cultura humana, la más prolongada, y la que más ha influido en la formación de las características duraderas de la raza, es, sin duda alguna, la del salvajismo. Junto con el salvajismo, en el tema que nos ocupa, hay que clasificar al barbarismo inferior, relativamente pacífico, que no se caracterice por hondas y agudas discrepancias de clase, o por un comportamiento continuo individual o de grupo orientado a hacerse con lo mejor del prójimo. Incluso en plena cultura bárbara -como, por ejemplo, durante la Edad Media-, los hábitos de vida y los intereses espirituales del grueso de la población continúan llevando el sello del salvajismo. La fase salvaje de la cultura es responsable de la mayor parte del ciclo biológico de la humanidad, en particular si el barbarismo inferior y la vida común del barbarismo posterior se contabilizan dentro del salvajismo, como, en parte, debería hacerse. Esto es especialmente cierto respecto de los elementos raciales que intervinieron en la composición de los pueblos dirigentes de la Cristiandad.

La cultura salvaje se caracteriza por la relativa ausencia de pragmatismo en las más altas generalizaciones de su conocimiento y de sus creencias. Como se ha señalado más arriba, sus creaciones teóricas son principalmente de naturaleza mitológica, fundiéndose con la tradición popular. Esta ingeniosa narración de historias apócrifas es, a lo sumo, una formulación amable e ineficaz de experiencias y observaciones en términos de algo parecido a un ciclo biológico de los fenómenos observados. Por una parte, tiene escaso valor y escasa utilidad en el terreno de la conveniencia pragmática, y, por consiguiente, no guarda una semejanza estrecha con el esquema de vida pragmático bárbaro; por otra, también es inútil como conocimiento sistemático de lo real. Se trata de una búsqueda de conocimiento, tal vez de conocimiento sistemático, y se produce a impulsos de la curiosidad ociosa. En este aspecto, encaja en la misma clase que la ciencia del hombre civilizado, pero no persigue el conocimiento en términos de un realismo opaco, sino en términos de alguna suerte de vida espiritual atribuida a los hechos. Es romántico y hegeliano antes que realista y darwiniano. Las necesidades lógicas de su esquema de pensamiento son necesidades de consistencia espiritual, más que de equivalencia cuantitativa. Se asemeja a la ciencia en cuanto que no tiene ningún motivo más allá del afán ocioso de una correlación sistemática de datos; pero difiere de ella en cuanto que su estandarización y la correlación de datos se establecen en términos del libre juego de una iniciativa personal imputada, más que sobre la base de la limitación a la causa y al efecto objetivos.

Debido a la prolongada disciplina selectiva de esta fase cultural del pasado, la naturaleza de la humanidad civilizada todavía es básicamente la naturaleza humana del hombre salvaje. El antiguo material de aptitudes e inclinaciones congénitas permanece sustancialmente inmutable, si bien encubierto por 
las tradiciones y los convencionalismos bárbaros, y reajustado por la habituación a las exigencias de la vida civilizada. En parte, por tanto, aunque no totalmente, la búsqueda científica, junto con la herencia salvaje, es innata en el hombre civilizado, ya que dicha búsqueda procede de acuerdo con el mismo motivo general, la curiosidad ociosa, que guiaba a los creadores salvajes de mitos, aunque utiliza conceptos y patrones ajenos, en gran medida, al hábito de pensamiento de los forjadores de mitos. La antigua predilección humana por descubrir un juego dramático de pasión y de intriga en los fenómenos de la naturaleza continúa imponiéndose. En las comunidades más avanzadas, e incluso entre los adeptos a la ciencia moderna, surge de forma persistente la reacción de la naturaleza salvaje contra el carácter inhumanamente desapasionado de la búsqueda científica, así como contra la índole implacable de los procesos tecnológicos que han brotado de esta búsqueda del conocimiento realista. Con gran frecuencia, la necesidad salvaje de una interpretación (dramatización) espiritual de los fenómenos rompe la corteza de los hábitos de pensamiento materialistas adquiridos para buscar refugio en artículos de fe mantenidos por la fuerza de la convicción instintiva. La ciencia y sus creaciones son más o menos misteriosas, más o menos ajenas a esa costumbre de insaciable afán de conocimiento que, en razón de una antigua herencia, anima a la humanidad. Furtiva o abiertamente, los hombres todavía buscan consuelo en los artículos maravillosos de la tradición salvaje, los cuales, sin poner en duda el dominio de la ciencia moderna, contradicen, sin embargo, las verdades de ésta, por traspasar sus hallazgos los límites de su sensibilidad espiritual alimentada por la jungla.

Los antiguos senderos del pensamiento y de la convicción salvajes son llanos y fáciles; sin embargo, por placenteras e indispensables que sean las formas arcaicas de pensamiento para la paz mental del hombre civilizado, es tal la fuerza arrolladora del análisis realista y de la inferencia bajo condiciones modernas, que los hallazgos de la ciencia, en conjunto, no son puestos en tela de juicio. Después de todo, el nombre de la ciencia es una palabra que hay que conjurar. Aunque sólo sea porque, al menos su nombre y sus manierismos, han invadido todos los campos del saber, e incluso han irrumpido en territorio perteneciente al enemigo. Por tanto, tenemos las «ciencias» de la teología, del derecho y de la medicina, como señalábamos anteriormente. Y existen cosas tales como ciencia cristiana, y astrología y quiromancia «científicas», etc. Pero, dentro del campo del saber propiamente dicho, hay una predilección similar por una atmósfera de precisión y rigor científicos en terrenos que no pertenecen a la ciencia. Tanto es así que incluso esa amplia variedad de conocimiento que tiene que ver más con la información general que con la teoría - lo que se denomina vagamente erudición - tiende poderosamente a adquirir el nombre y las formas de las afirmaciones teóricas. Por marcado que sea el contraste entre estas ramas del saber, de una parte, y la ciencia propiamente dicha, de otra, incluso la formación clásica, y las humanidades en general, incurren cada vez más en esta predilección, a medida que van 
sucediéndose las generaciones de estudiantes. Los estudiantes de literatura, por ejemplo, se inclinan cada vez más a sustituir, como meta de sus esfuerzos, esa disciplina del gusto y ese sentido cultivado de la forma y del pensamiento literarios - que deben seguir siendo siempre el propósito principal de la enseñanza literaria para distinguirla de la filología y de las ciencias socialespor el análisis crítico y la especulación lingüística. Naturalmente, no hay intención de poner en duda la legitimidad de la filología o de una ciencia relativa al estudio analítico de la literatura como un hecho de la historia cultural, pero estas cosas no equivalen a una formación en el gusto literario, ni pueden tampoco ocupar su lugar. El efecto de este esfuerzo por alcanzar formulaciones científicas en un terreno extraño al espíritu de la ciencia es tan curioso cuanto devastador. Científicamente hablando, estas investigaciones cuasi-científicas necesariamente comienzan en la nada y terminan en el mismo sitio, mientras que en cuestión de beneficio cultural no suelen convertirse en nada mejor que abnegación espiritual. Mas estos ciegos esfuerzos por ajustarse a las normas de la ciencia sirven para demostrar cuán amplia y profunda es su influencia en la moderna comunidad.

La erudición - es decir, una familiaridad íntima y sistemática con los logros del pasado cultural- conserva todavía su puesto en el esquema del saber, a pesar de los imprudentes esfuerzos de los cortos de vista por mezclarla con el trabajo de la ciencia, porque permite sacar partido de las antiguas inclinaciones geniales que guiaban a los hombres en la búsqueda del conocimiento, antes del advenimiento de la ciencia o del declarado pragmatismo bárbaro. Puede que su lugar no sea tan grande, en proporción a todo su campo del saber, como lo era antes de que la era científica se abriera paso definitivamente. Pero no existe un antagonismo intrínseco entre la ciencia y la erudición, como el que existe entre la formación pragmática y la investigación científica. La erudición moderna comparte con la ciencia moderna la cualidad de no ser pragmática en sus metas. Al igual que la ciencia, no tiene un propósito ulterior. Quizá sea difícil trazar la línea divisoria entre la ciencia y la erudición, y puede ser incluso innecesario; al menos mientras las dos clases de disciplinas permanezcan unidas en muchos aspectos, mientras existan numerosos puntos de contacto y de afinidad entre ambas, y mientras que las dos juntas configuren el esquema moderno del conocimiento; sin embargo, no hay necesidad de confundirlas entre sí, así como tampoco la primera puede hacer el trabajo de la segunda, o viceversa. El esquema de saber ha cambiado hasta el extremo de conceder a la ciencia el lugar predominante, pero no por ello ha sido invadido el dominio del erudito, ni tampoco ha sufrido una contracción a manos de la ciencia, sea lo que fuere lo que pueda decirse de la abnegación carente de personalidad de aquellos cuyo lugar, si es que tienen alguno, está en el campo de la erudición más que en el de la ciencia.

Todo lo que se ha expuesto hasta aquí no tiene, naturalmente, nada que decir respecto de los méritos intrínsecos de esta búsqueda de conocimiento realista. En realidad, la ciencia da su carácter a la cultura moderna. Se puede 
aprobar o desaprobar el hecho de que esta interpretación opaca, materialista de las cosas invada el pensamiento moderno. Es una cuestión de gusto, y ya se sabe que sobre gustos no se discute. El predominio de esta investigación realista es una característica de la cultura moderna, y la actitud adoptada por los críticos respecto de este fenómeno es muy significativa, ya que indica hasta qué punto su propia mentalidad coincide con el sentido común ilustrado de la humanidad civilizada. Esto pone de relieve hasta qué extremo siguen el ritmo del progreso de la cultura. Aquellos en quienes la predilección salvaje o la tradición bárbara sea más fuerte que su habituación a la vida civilizada, encontrarán perverso este factor dominante de la vida moderna, tal vez incluso calamitoso; aquellos cuya mentalidad se haya formado al compás del proceso mecánico y de la investigación científica, probablemente lo considerarán bueno. La moderna cultura occidental, con su esencia de conocimiento realista, puede ser mejor o peor que algunos otros esquemas culturales, tales como el griego clásico, el cristiano medieval, el hindú o el de los indios Pueblo. Examinada desde una cierta perspectiva, contrastada con unos determinados patrones, es sin duda mejor; con otros, en cambio, es peor. Pero permanece el hecho de que el actual esquema cultural, en su desarrollo más maduro, es de este cariz; su fuerza característica reside en esta concepción realista; su disciplina superior y sus aspiraciones más maduras son éstas.

En realidad, el sentido común equilibrado de la humanidad civilizada no acepta otro objetivo de conducta como autosuficiente y definitivo. Que éste sea el caso parece deberse, ante todo, a la omnipresencia de la tecnología mecánica y a sus creaciones en la vida de las comunidades modernas. Y mientras el proceso mecánico continúe ocupando su posición dominante como factor disciplinario en la cultura moderna, la vida espiritual e intelectual de esta era cultural mantendrá el carácter que le imprimió el proceso mecánico.

Pero aunque el espíritu del científico y sus logros despierten una admiración sin reservas en el hombre moderno, y a pesar de que sus descubrimientos resulten más convincentes que cualquier otra cosa, esto no significa que el comportamiento del hombre, producido o exigido por esta búsqueda del conocimiento, esté cerca de responder al vigente ideal de la humanidad, o que sus conclusiones tengan que ser consideradas tan buenas y hermosas cuanto verdaderas. El hombre ideal, y el ideal de la vida humana, incluso en la comprensión de aquellos que más se regocijan de los avances de la ciencia, no es el escéptico melindroso del laboratorio, ni la regla de cálculo viva. La búsqueda de la ciencia es relativamente nueva. Se trata de un factor cultural no incluido, con su fuerza moderna, entre aquellas circunstancias cuya acción selectiva en el pasado más remoto han dado a la raza la naturaleza humana que ahora tiene. La raza alcanzó el umbral humano con un escaso bagaje de este minucioso conocimiento de los hechos; y a través de la mayor parte de su ciclo biológico posterior se ha acostumbrado a construir sus más altas generalizaciones y a formular sus principios existenciales más amplios en unos términos que no son los del realismo desapasionado. Esta forma de conocimiento atraía 
crecientemente la atención del hombre en el pasado, puesto que tiene una influencia decisiva en los asuntos más intrascendentes de la vida cotidiana; pero nunca hasta ahora había sido colocada en primer lugar, como la nota dominante de la cultura humana. El hombre común, tal como es por su herencia, tiene, por tanto, un buen motivo para permanecer bajo su dominio.

(Traducción: Margarita Barañano.) 
CRITICA DE LIBROS 